\title{
Study on Dynamic Configuration of the Rights of Enterprise Internal Control
}

\author{
Wei Zhong (Corresponding author) \\ Research Institute for Fiscal Science, Ministry of Finance \\ Xinzhi Mansion, 28 Fucheng Road, Haidian District, Beijing 100142, China \\ Tel: +86-10-8819-0427Ｅ-mail: zhongwei82981@sina.com.cn \\ Shilei Zhang \\ Research Institute for Fiscal Science, Ministry of Finance \\ Xinzhi Mansion, 28 Fucheng Road, Haidian District, Beijing 100142, China \\ Tel: +86-10-8819-0427Ｅ-mail: zs1365@163.com
}

Received: August 16, $2010 \quad$ Accepted: August 24, $2010 \quad$ doi:10.5430/ijfr.v1n1p44

\begin{abstract}
Internal controls will be the tools of the managements who want to gain personal benefits when defects exist in its design and power distribution, and it doesn't accord with the fact and holds back the initiative of managements when their internal control power is taken back. Then, internal control power boundary must be proper so that it can serve for the interests of investors. This paper constructs the model of dynamic distribution of internal control power before relevant factors which affect power distribution are discussed. Based on model, the relevant rights of internal controls between the investors and the managements are tried to be re-allocated dynamically. Finally, factors which affect the efficiency and effectiveness of internal controls are analyzed and summarized.
\end{abstract}

Keywords: Internal control, Dynamic configuration of rights, Moral hazard, Adverse selection

\section{Introduction}

In addition to its functional position, the allocation of resources plays an important role for the implementation of "internal control" in management practice, and the "resources" here include resources of enterprise itself, such as specialized information system, personnel, office sites, etc., more importantly, issues of rights distribution are included in internal control itself. From the perspective of institutional economics, there are two levels of contracts in internal control, the first level is the contracts between business owners (or investors) and the management, and the second level is the contracts between the corporate management and the executors of internal control which are the specific provisions of the implementation of the internal control inside each enterprise, undoubtedly both contracts are incomplete (Note 1). The author believes that the first level of contract design focuses on the incentives and constraints, while the second level of contract design focuses on the prevention of conspiracy and collusion. From the perspective of dynamic configuration of control rights, the model will be built and the issue of the distribution of internal control rights will be studied in the paper.

Article XII of "Basic Standard of Enterprise Internal Control" of China stipulates: The Board is responsible for the establishment of sound internal controls and effective implementation. Board of Supervisors establishes and monitors the implementation of internal control of the board of directors. Managers are responsible for organizing and leading the daily operations of the internal control. Enterprises should set up specialized agencies or designate appropriate department responsible for organizing and coordinating the specific establishment and the implementation of the internal controls and daily work. Article XIII stipulates: Enterprises should establish an audit committee under the board of directors. Audit committee is in charge of reviewing internal controls, monitoring the effective implementation of internal control and self-assessment of the internal control, coordinating the internal control audit and other related issues. It is obvious that the distribution of the main rights of internal control is established by the board of directors, the managers are responsible for operation, while the supervisory board and the audit committee are responsible for supervision mechanism. This distribution actually makes the best use of the traditional corporate governance structure 
and distributes the internal control rights in accordance with roles of the governance structure and strengthens the rights of original roles and ensures the relevant stakeholders to have a clear division of roles of the internal control. This distribution also brings two problems. First, whether the internal control system established by the board of directors is effective. The Principal-agent Theory suggests that corporate management has more information of business management than the shareholders and board of directors, while the board has neither its management expertise nor information superiority compared with the corporate management, it is questionable whether the internal control system established by the board can grasp the key points and meet the actual business requirements of the enterprise. Second, whether the management solely responsible for the daily operation of internal control is appropriate. The phenomenon of internal members controlling of state-owned enterprises in China is serious which is caused by the absence of owners and internal control has precisely the main functions of preventing moral hazard of the management and employees, hence it is apparent that if the design and distribution of internal control rights has deficiencies, then it will become a tool for the management to gain private benefits, but if all of the internal control operation rights are taken back from the management, it will stifle the initiative of its functions, and it does not conform to objective reality as well, then how to define the rights of internal control of the management to an appropriate scope to serve for the maximum benefits of the investors. The paper will explore the relevant factors which impact its configuration of rights and try to solve the problem above by constructing the internal control rights allocation models.

\section{Derivation of the internal control rights distribution model}

Suppose the probability of success of a business to be $\mathrm{p}$, at the time the revenue generated as $\mathrm{R}$, if the management is responsible enough to fulfill the duty, then the company's success probability $p=p_{H}$, if fraud exists the management, then $p=p_{L}$, then management's private benefits as $B$, and $\Delta p=p_{H}-p_{L}$, if the business fails then the revenue is 0 , the management takes due diligence strategies, i.e. when $\Delta \mathrm{pR}>\mathrm{B}$ is an efficient outcome. To achieve this result, investors can take appropriate compensatory measures, assuming that investors compensate for the management as $\mathrm{W}$, as long as $\Delta \mathrm{pW} \geq \mathrm{B}$, the management will be induced to accept $\mathrm{W}$ and give up $\mathrm{B}$, as a result the efficient allocation can be achieved. And then we assume that investors introduce an effective arrangement of internal control system, setting the validity as $\beta$, then the probability of business success $\mathrm{p}=\beta \mathrm{p}_{\mathrm{H}}$, due to the establishment of internal control, the management gets the corresponding rights $\lambda$, assuming $\lambda \in[0,1]$, when $\lambda=1$, the management has complete control, while $\lambda=0$, the shareholders have full control, private income of the management changes into $\mathrm{B}=\mathrm{m} \lambda$ in which $\mathrm{m}$ stands for the coefficient of the actual exercise of control by the management under the established control rights distribution. Meanwhile, assuming the construction cost of the internal control system as $\Phi$, the corresponding $\beta$ is an increasing function of $\Phi, \Phi$ is a decreasing function of $\lambda$, may as well set $\Phi=-\mathrm{k} \lambda(\mathrm{k}>0)$ i.e. the more cost is invested, the more effective internal control is in the future, the smaller the corresponding rights of control of the management become. After the establishment of internal control system, there must be complemented audit and supervision mechanisms. Assuming audit and supervision cost as A, at the same time, the more perfect the design of supervision is, the higher the cost is, the smaller the corresponding rights of control of the management become. Assuming $A=-i \lambda(i>0$ ) and investors expect earnings as $R_{0}$, then conditions for investment for the business establishment by the investor: $\beta p_{H}$ (R-B / $\Delta \mathrm{p})-\mathrm{A}-\Phi \geq \mathrm{R}_{0}$, after the incorporating and rearranging:

$$
\begin{gathered}
\beta p_{H}(R-m \lambda / \Delta p)+i \lambda+k \lambda \geq R_{0} \\
-\left(\beta p_{H} m / \Delta p+i+k\right) \lambda \geq R_{0}-\beta p_{H} R \\
\text { because } \Delta p W \geq B, \lambda \geq 0,
\end{gathered}
$$

then

$$
\frac{\left(\beta p_{H} R-R_{0}\right) \Delta p}{\beta p_{H} m+(i+k) \Delta p}
$$

The Principal-agent Theory suggests that because the corporate management has more internal information and business management experience than the investors, they tend to have more control compared with investors, but on the other hand, too many rights are bound to increase the motivation and probability of managers' pursuit of private benefits at the expense of business interests, so in order to achieve the maximization of corporate interests their control rights must be restrained to reasonable limits. As for internal control, the power may include the organization coordination right of establishment and implementation of internal control, and leadership of internal control operation. If the configuration of the rights mentioned above for the management is too high, in addition to increasing their motivation for fraud, it will lead to management's attempt of higher risk and seriously increase the agency costs. On the contrary, if the rights allocation is too low, it will make the management tend to be the role of general staff, lacking space for innovation, 
killing the so-called "entrepreneurial spirit."

\section{Analysis on the related factors affecting configuration of the internal control rights of the management}

$3.1^{\frac{\partial \lambda}{\partial i}} \prec 0, \frac{\partial \lambda}{\partial k} \prec 0$

Two formulas above show that the higher the construction cost of internal control and audit supervision costs are, the smaller rights of internal control the management has. For example, in 2002, for Enron and WorldCom's financial fraud cases, the U.S. Congress enacted the "2002 Public Company Accounting Reform and Investor Protection Act" (i.e. Sarbanes-Oxley Act of 2002). Article 302 of the Act provides that for the company making the preparation of reports in accordance with the "Securities Exchange Act of 1934", when its chief executive officer and chief financial officer submit reports, at the same time the evidence report of establishing, maintaining and evaluating of the internal controls should be submitted as well. Article 404 (a) requires that the management of listed company should make assessment in the final financial reports of the effectiveness of internal control over financial reporting. Article 404 (b) requires that the accounting firm responsible for the audit report of the company shall test and evaluate the report on internal control of the management and issue evaluation report. In 2002, SEC had done a preliminary implementation cost estimates on Article 404: " the information revealing cost of all the listed companies is up to 49.5 million U.S. dollars, the annual and quarterly reports of each company increase 5 additional work hour in average s." August 2003, SEC revised its estimate: the total annual cost of the implementation of Article 404 was about 1.24 billion U.S. dollars, an average of 91,000 U.S. dollars per company, 383 hours increased. However later investigations revealed that the implementation cost is far higher than expectation. In order to achieve the Act provisions, the cost of listed companies increased by $40 \%$ in average, and the average cost to establish internal control systems of large U.S. companies in the first year were as high as 4.3 million U.S. dollars. In order to fulfill Article 404, the cost of General Electric was as high as 3 million U.S. dollars. After a survey of the Act, for different social groups tend to show different interests. Among government officials and representatives of regulatory agencies, $40 \%$ oppose, $60 \%$ support, representatives from the regulatory agencies are more positive on 404 . Representatives from enterprises $50 \%$ oppose, $50 \%$ support. It is obvious that compared with other stakeholders, the management questions the Act even stronger, in addition to consideration of the Act of rationality itself, it also to some extent reflects the dissatisfaction and concern of reducing their control to some extent by increasing input costs and strengthening internal controls.

$$
3.2 \frac{\partial \lambda}{\partial m}=\frac{-m}{\left[\beta p_{H} m+(i+k) \Delta p\right]^{2}} \prec 0
$$

The actual exercise of control power of the management is impacted by the reasonableness of internal control system, in addition to which, the extent of demands for the capture of private control profits is one of the important factors affecting $\mathrm{m}$. for the listed companies in China, from the enterprise internal point of view, widespread "absence of owner" phenomenon, chairman who exercises stock rights on behalf of the State and the country have the same contradiction of the principal-agent, with its inadequate internal control system, "internal members controlling" phenomenon is a very serious problem for the listed company. The incidence of moral hazard and adverse selection greatly increase the probability. From the external environment point of view, in China the market of professional managers, property rights trading market and bankruptcy mechanisms are far from perfect, the mandatory disclosure of internal control system is also in its state of exploring. The stakeholders outside the firm are unable to know the internal control information, which makes corporate management embolden to capture private benefits. Taking into account the current situation, investors should give less internal control rights to the management and strengthen assessment of supervision mechanisms, under the circumstance of not impacting on the management's work performance and motivation, making the value of $\mathrm{m}$ down to reasonable levels.

$3.3 \frac{\partial \lambda}{\partial \beta}=\frac{p_{H} \Delta p R\left[\beta p_{H} m+(i+k) \Delta p\right]-p_{H} \Delta p m\left(\beta p_{H} R-R_{0}\right)}{\left[\beta p_{H} m+(i+k) \Delta p\right]^{2}}$

$$
\begin{gathered}
\text { Rearranged: } \\
\frac{\partial \lambda}{\partial \beta}=\frac{p_{H} \Delta p\left[(i+k) \Delta p R+R_{0} m\right]}{\left[\beta p_{H} m+(i+k) \Delta p\right]^{2}} \succ 0 \\
\text { Similarly: } \frac{\partial \lambda}{\partial p_{H}} \succ 0
\end{gathered}
$$


The more complete and effective internal control is, the more appropriate control rights the management should be given. On the internal control evaluation, China's newly released "Internal Control Assessment Guidelines (Draft)" involves the following aspects: (1) whether internal controls are based on risk assessment covering the risks of the enterprise level and all the important aspects of business processes. (2) whether internal control design methods are appropriate, whether time schedule of internal controls construction is scientific, whether the requirements for phased work are reasonable. (3)whether design and operation of internal control are effective, whether staffing, division of responsibilities and authorization are reasonable. (4) whether evaluated departments carry out internal control self-examination and submit the relevant self-examination report. (5) whether evaluated departments establish favorable policies and measures to promote the implementation of internal controls and problem correction mechanism. (6) whether during the evaluation, evaluated departments occur serious risks and accidents. Of course, some of these specific criteria yet need to be tested in practice, from the perspective of institutional economics, the more effective the system is, the more helpful for it will be to save transaction costs, and the internal control system is as the same, built on the basis of effective internal controls, appropriate decentralization can reduce the risk of the management's seizing private benefits and infringing the interests of investors, playing the greatest incentive role of the system itself.

On the partial derivative of $\mathrm{pH}$ is greater than zero, the management of more due diligence should be given more control rights. Whether the management is of due diligence or not, in addition to the influence by their subjective intention, the "entrepreneurship" is also a very important aspect. To a certain extent, the implementation of their rights of internal control and allocation of resources are the embodiments of entrepreneurship. By giving the management the some rights of design of internal control, it will not only save investors related costs, but also stimulate the initiative and creativity of the management, and it will make internal control system more operational. The final results of the implementation of can be the embodiment of entrepreneurship, and it provides valuable reference information to investors' related power configuration.

$3.4 \frac{\partial \lambda}{\partial \mathrm{R}_{0}}=\frac{-\Delta p}{\beta p_{H} m+(i+k) \Delta p} \prec 0$

From this it can be concluded that investors' higher expectations lead to smaller rights of corresponding internal control given to the management. From these internal controls rights distribution and rationality of internal control derivation, the two are positively correlated, while the rationality of internal control system can be studied reversely from the point of internal control deficiencies. By studying 10000 companies, internal control deficiencies were disclosed in 145 companies. Ge\&McVay (2005) found that internal control deficiencies and the complexity of organizational structure are positively correlated, while internal control deficiencies and the enterprise life cycle and profitability are in a negative correlation between. The more deficiencies internal control has, the smaller future earnings investors expect, and then the complexity of organizational structure should be reduced, and internal control rights of the management should be limited.

\section{Conclusion}

Based on the study of internal control system, the dynamic configuration models of internal controls rights are established, and based on the model, internal control rights are re-allocated between the investors and the management, and finally various factors which impact internal control efficiency and effectiveness are summed up. Question of the distribution of internal control is essentially the issue of rights configuration of incomplete contracts principle agent. Because control right in itself is difficult to be quantified, meanwhile the internal control information disclosure system of listed company is still in the exploratory stage, which makes it impossible to carry out the relevant evidence research, this is a flaw in this article. Hope that with the gradual improvement of internal control system of Chinese enterprises, the research can be continued.

\section{References}

Demsetz, Harold, Lehn \& Kenneth. (1985). The Structure of Corporate Ownership: Causes and Consequences. The Journal of Political Economy, 93, 1155-1177

Fan, J. P. H., and T. J. Wong. (2002). Corporate ownership structure and the informativeness of accounting earnings in East Asia. Journal of Accounting Economics, 33, 401-425.

Ge, W., and S. McVay. (2005). The disclosure of material weaknesses in internal controls after the Sarbanes-Oxley Act. Accounting Horizons, 19 (3), 137-158

Grossman S, Hart O. (1986). The costs and Benefits of Ownership: A Theory of Vertical and Lateral Integration. Journal 
of Political Economy, 94 (4), 691-719

Huang Jingjing. (2005). Comments on Controversial Arguments on the Implementation Cost of Article 404 of the United States SOA. Accounting Research, 6, 86-89

Jeffrey T. Doyle, Weili Ge,Sarah McVay. (2007). Accruals Quality and Internal Control over Financial Reporting. Accounting Review, 82, 1141-1170

Li Weian. (2000). Corporate Governance. Tianjin: Nankai University Press. pp. 74-81

\section{Notes}

Note 1. According to Grossman \& Hart (1986) point of view: the fundamental difference of complete contracts and incomplete contracts is that the former is able to stipulate the authority and responsibility of parties in a variety of possible conditions in advance, so its concern is the issue of supervision, while the latter refers to that the contract cannot stipulate the authority and responsibility of parties in a variety of possible conditions and thus it needs the re-negotiation mechanism to solve after the natural state occurs. Therefore, its focus lies on mechanism design in advance or institutional arrangements of the rights. 